\title{
17 $\beta$-estradiol protects INS-1 insulinoma cells from mitophagy via $G$ protein-coupled estrogen receptors and the PI3K/Akt signaling pathway
}

\author{
LIANG ZHANG $^{1}$, YUYAN ZHAO ${ }^{1}$ and LEI GUO $^{2}$ \\ Departments of ${ }^{1}$ Endocrinology and ${ }^{2}$ Orthopedic Surgery, The First Affiliated Hospital, \\ China Medical University, Shenyang, Liaoning 110001, P.R. China
}

Received December 10, 2016; Accepted December 29, 2017

DOI: $10.3892 / \mathrm{ijmm} .2018 .3470$

\begin{abstract}
E2) is a steroid hormone that is known to exert effects on blood glucose homeostasis. The $\mathrm{G}$ protein-coupled estrogen receptor (GPER) has been identified as a non-genomic estrogenic receptor, and is involved in numerous physiological processes, including cell survival, energy provision and metabolism. 17 $\beta$-E2 may decrease apoptosis by binding to the GPER. The phosphoinositide 3-kinase (PI3K)/Akt signaling pathway is involved in physiological and pathological functions such as autophagy. The purpose of the present study was to investigate the role of the PI3K/Akt signaling pathway in the mediation of the effects of GPERs, and the effects of $17 \beta-E 2$ on mitophagy in INS-1 cells, a rat insulin-secreting $\beta$-cell line. In vitro, INS-1 cells were treated with different concentrations of $17 \beta-\mathrm{E} 2$ with and without pretreatment with a GPER antagonist (G15) or PI3K antagonist (LY294002) and compared with a negative control. An immunofluorescence assay demonstrated that GPERs are expressed in INS-1 cells. Western blot assays demonstrated that $17 \beta-E 2$ increased GPER levels and the phosphorylation
\end{abstract}

Correspondence to: Professor Yuyan Zhao, Department of Endocrinology, The First Affiliated Hospital, China Medical University, 155 Nanjing North Street, Shenyang, Liaoning 110001, P.R. China

E-mail: G572@sina.com

Professor Lei Guo, Department of Orthopedic Surgery, The First Affiliated Hospital, China Medical University, 155 Nanjing North Street, Shenyang, Liaoning 110001, P.R. China

E-mail: 15241818899@163.com

Abbreviations: 17 $\beta$-E2, 17 $\beta$-estradiol; GPER, G protein-coupled estrogen receptor; INS-1 cells, insulin-secreting $\beta$-cell line; TOM20, the translocase of the mitochondrial outer membrane complex 20; LAMP2, lysosomal-associated membrane protein 2; Hsp60, mitochondrial heat-shock protein 60 ; LC3, microtubule-associated protein-1 light chain 3

Key words: 17ß-estradiol, G protein-coupled estrogen receptor, PI3K/Akt pathway, mitophagy of Akt. Transmission electronic microscopy revealed that $17 \beta$-E2 reduced the formation of mitophagosomes and autophagosomes in INS-1 cells. An immunofluorescence staining assay indicated that the co-localization of translocase of mitochondrial outer membrane complex 20 (TOM20) with lysosomal-associated membrane protein 2 (LAMP2) was decreased in INS-1 cells treated with $17 \beta-\mathrm{E} 2$ alone. Western blotting demonstrated that $17 \beta-\mathrm{E} 2$ reduced the protein levels of activated microtubule-associated protein-1 light chain 3, and increased those of TOM20 and mitochondrial heat-shock protein 60 . Notably, the protective effects of $17 \beta-\mathrm{E} 2$ were significantly diminished by G15 or LY294002. In conclusion, the present study suggests that $17 \beta$-E2 activates the PI3K/ Akt pathway via the GPER in INS-1 cells. Furthermore, $17 \beta$-E2 may be involved in mitophagy by the regulating the GPER/PI3K/Akt pathway.

\section{Introduction}

Pancreatic $\beta$ cells are key regulators of the process of glucose tolerance, and proper $\beta$ cell function is essential for the maintenance of blood glucose homeostasis. Notably, defects in the mass and function of $\beta$ cells are required for type 2 diabetes to develop (1). In the early phase of glucose metabolism abnormality, the levels of blood sugar are kept relatively stable through the compensatory function of islet $\beta$ cells. When the limits of this compensatory function are exceeded, apoptosis of the pancreatic $\beta$ cells increases (2). The mechanism may be associated with disorders of mitochondrial function, oxidative stress and elevated levels of proinflammatory cytokines (3). In vivo, estrogen treatment has been demonstrated to decrease $\beta$ cell apoptosis and restore a certain degree of insulin secretion in mice (4). Estrogen is a steroid hormone that serves an important role in physiological processes by binding with intracellular receptors. However, estrogen receptors on the membranes of pancreatic $\beta$ cells are not yet completely understood. The existence of a non-classical membrane estrogen receptor has been described by Nadal et al (5) and Ropero et al (6). Other researchers have suggested a possible role for G-protein coupled receptor 30 (GPR30) as an estrogen receptor involved in the effects of estrogen in the endocrine pancreas $(7,8)$. In the review conducted by Ropero et al (9), 
a model for the roles of estrogen receptor $\beta$ and GPR30 in the physiology of the endocrine pancreas was presented, and it was suggested that the GPR30 is expressed in mice and rat pancreatic $\beta$ cells. GPR30 is a $17 \beta$-estradiol (17 $\beta$-E2)-binding receptor, which is also known as the $G$ protein-coupled estrogen receptor (GPER) (10). The 17 $\beta$-E2-mediated activation of the GPER stimulates intracellular calcium mobilization and phosphoinositide 3-kinase (PI3K) activation (11). The functions and importance of the GPER in pancreatic function and glucose metabolism have been elucidated, which has revealed the therapeutic potential of GPER activity (12).

The PI3K/Akt pathway is normally activated by extracellular signals in physiological conditions, such as growth factors, cytokines and hormones. It has been demonstrated that $\mathrm{G}$ protein-coupled receptors directly stimulate the $\mathrm{p} 110 \beta$ and p110 $\gamma$ isoforms of PI3K via the $\beta \gamma$ subunits of heterotrimeric $\mathrm{G}$ proteins, and activate the p110 $\delta$ isoform of PI3K in $\beta$ cells by an unknown mechanism (13-15). For this reason, it would be interesting to detect whether $17 \beta-\mathrm{E} 2$ activates the PI3K/Akt signaling pathway via the GPER in an insulin-secreting $\beta$-cell line (INS-1).

Autophagy is a biological process by which cytoplasmic macromolecules and unnecessary organelles are degraded in membranous vesicles, and is a widely present biological phenomenaonin eukaryotes $(16,17)$. Autophagy serves an important role in various human diseases (18). It is becoming clear that the regulation of autophagic activity is associated with tumor formation and progression, and is also important to cancer therapy (19). In cancer cells, chemical inhibitors of autophagy increase the apoptosis induced by active-site mechanistic target of rapamycin (mTOR) inhibitors or dual PI3K/mTOR inhibitors, which suggests that the PI3K/Akt pathway has an important role in the process of autophagy $(20,21)$. Autophagy of the mitochondria, also known as mitophagy, is important for mitochondrial quality control, and thus is essential in cellular energy provision, calcium homeostasis, redox signaling and apoptotic signaling $(22,23)$. The health of the mitochondria is important, because mitochondria are essential to major cell metabolic pathways, and are a major cause of cell death (24). Mitochondrial dynamics, including fission and fusion, serve a key role in mitophagic signaling $(25,26)$. 17 $\beta$-E2 has been indicated to increase mitochondrial fusion, decrease fission processes and modify the normal development and function of mitochondria in $\mathrm{MCF}-7$ breast cancer cells (27). According to the review of Zhang (28), it is possible to visualize mitophagy by the co-localization of mitochondrial proteins with lysosomal markers.

The aim of the present study was to investigate whether $17 \beta$-E2 regulates the PI3K/Akt pathway through the GPER and whether $17 \beta-\mathrm{E} 2$ inhibits mitophagy by activating the GPER/PI3K/Akt signaling pathway and thereby protects INS-1 cells.

\section{Materials and methods}

Reagents. 17 $\beta$-E2 was obtained from Sigma-Aldrich (Merck KGaA, Darmstadt, Germany). RPMI-1640 medium and fetal bovine serum (FBS) were obtained from Gibco (Thermo Fisher Scientific, Inc., Waltham, MA, USA). The selective GPER antagonist (G15) was bought from Tocris Bioscience
(Minneapolis, MA, USA). The PI3K inhibitor (LY294002) and 4,6-diamidino-2-phenylindole (DAPI) were purchased from Beyotime Institute of Biotechnology (Jiangsu, China). GPER antibody [sc-48524-R; polyclonal, rabbit anti-mouse, rat, human; western blotting (WB) 1:200; immunofluorescence (IF) 1:50], lysosomal-associated membrane protein 2 (LAMP2) antibody (sc-8100; polyclonal, goat anti mouse, rat and human; IF 1:50), the translocase of the mitochondrial outer membrane complex 20 (TOM20) antibody (sc-11415; polyclonal, rabbit anti mouse, rat and human; WB 1:200, IF 1:50), microtubule-associated protein-1 light chain 3 (LC3) antibody (sc-376404; monoclonal, mouse anti mouse and rat; WB 1:100), and the mitochondrial heat-shock protein 60 (Hsp60) antibody (sc-1052; polyclonal, goat anti mouse, rat and human; WB 1:200) were all obtained from Santa Cruz Biotechnology, Inc. (Dallas, TX, USA). Total/phospho-Akt (t-Akt/p-Akt) polyclonal antibody (1:1,000; Ab8805/Ab8932) was obtained from Abcam (Cambridge, MA, USA). $\beta$-actin antibody (AF0003; monoclonal, mouse anti-human/mouse/ rat; WB 1:1,000) was acquired from Beijing Biosynthesis Biotechnology Co., Ltd. (Beijing, China). An immunofluorescence staining kit with Alexa Fluor 555-labeled donkey anti-rabbit immunoglobulin G ( $\lg G)$ (P0179) was purchased from Beyotime Institute of Biotechnology. IFKine ${ }^{\circledR}$ Green conjugated donkey anti-goat IgG (A24231) was obtained from Abbkine Scientific Co., Ltd. (Redlands, CA, USA).

Cell culture. The rat insulin-secreting $\beta$-cell line (INS-1) was obtained from China Infrastructure of Cell Line Resources (Beijing, China) and maintained in RPMI-1640 medium supplemented with $10 \%$ FBS, L-glutamine, $50 \mathrm{mg} / \mathrm{ml}$ penicillin and $100 \mathrm{mg} / \mathrm{ml}$ streptomycin (Beyotime Institute of Biotechnology). The cells were grown in a humidified atmosphere containing $5 \% \mathrm{CO}_{2}$ at $37^{\circ} \mathrm{C}$. Prior to the experiment, the INS-1 cells were grown in Petri dishes in a serum-free medium for $24 \mathrm{~h}$. The following day, the INS-1 cells were treated with different concentrations of 17 $\beta$-E2 $(0,1,10$ and $100 \mathrm{nM})$, or with $100 \mathrm{nM} 17 \beta-\mathrm{E} 2$ plus $15 \mu \mathrm{M}$ G15 or $20 \mu \mathrm{M}$ LY294002 for 24 h, respectively. For the combination treatments, the cells were pretreated with G15 or LY294002 for 30 min prior to treatment with $17 \beta-\mathrm{E} 2$.

IF analysis. The INS-1 cells were fixed in 4\% paraformaldehyde buffered with $0.1 \mathrm{M}$ phosphate $(\mathrm{pH} 7.3)$ for $30 \mathrm{~min}$ at room temperature and then washed with phosphatebuffered saline (PBS). The cells were permeabilized with $0.1 \%$ Triton X-100 for $30 \mathrm{~min}$ and washed with PBS. Following blocking with $5 \%$ bovine serum albumin (Gibco) in Tris-buffered saline with Tween-20 (TBST) for $30 \mathrm{~min}$ at room temperature, the INS-1 cells were incubated with specific primary antibodies targeting LAMP2, TOM20 and GPER overnight at $4^{\circ} \mathrm{C}$. The next day, the INS-1 cells were washed with PBS and then incubated with donkey anti-goat $\operatorname{IgG}(1: 1,000)$ or donkey anti-rabbit $\operatorname{IgG}(1: 1,000)$ secondary antibody for $30 \mathrm{~min}$ at $37^{\circ} \mathrm{C}$. Subsequently, the cells were stained with DAPI for $5 \mathrm{~min}$ at room temperature. After washing with PBS for $15 \mathrm{~min}$, the stained cells were viewed using an Olympus FV1000 confocal laser-scanning microscope (Olympus Corporation, Tokyo, Japan) with peak emission wavelengths of $518 \mathrm{~nm}$ (green) and $565 \mathrm{~nm}$ (red). 
DAPI

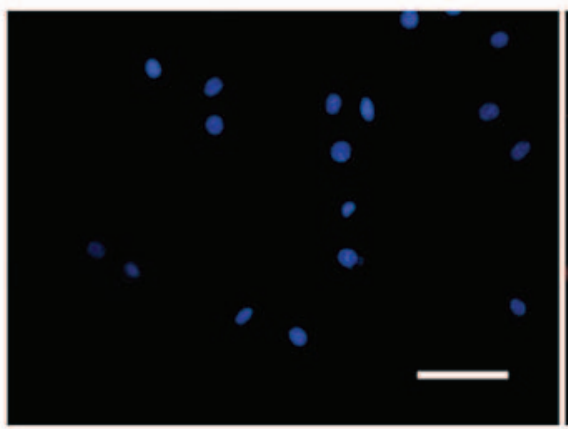

GPER

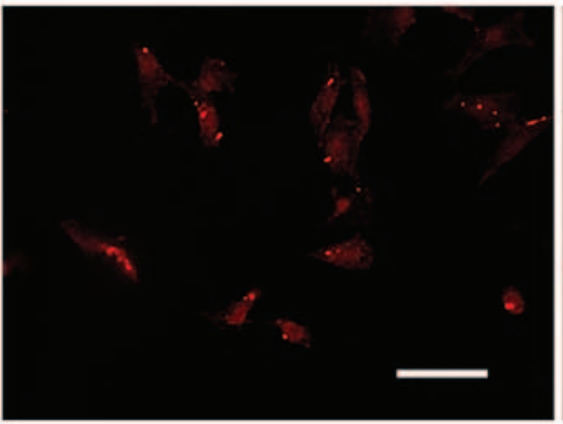

Merged

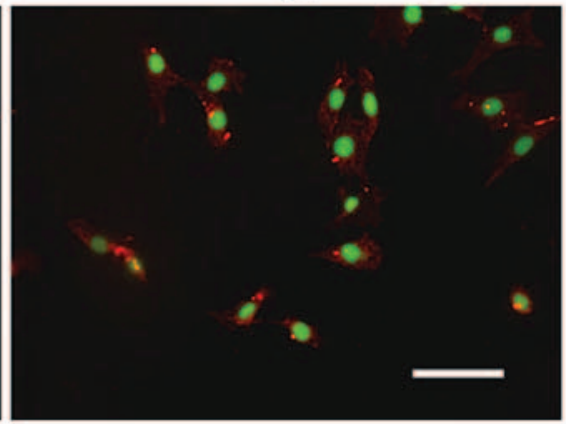

Figure 1. GPER is expressed in INS-1 cells. Immunofluorescence staining of INS-1 cells for GPER (red). Nuclei were stained with DAPI (blue). Results are representative of three different experiments. Scale bar, $10 \mu \mathrm{m}$. GPER, G protein-coupled estrogen receptor; INS-1, rat insulin-secreting $\beta$-cell line; DAPI, 4',6-diamidino-2-phenylindole.

Analysis using transmission electron microscopy (TEM). The cells were treated and collected by trypsinization, fixed with $2.5 \%$ phosphate-buffered glutaraldehyde at room temperature for $4 \mathrm{~h}$, and post-fixed in $1 \%$ phosphate-buffered osmium tetroxide at $4^{\circ} \mathrm{C}$ for $1.5 \mathrm{~h}$. The cells were embedded using Epon 812 epoxy resin at room temperature overnight, sectioned, double stained with uranyl acetate and lead citrate at room temperature for $23 \mathrm{~min}$, and analyzed using a JEM-1200EX transmission electron microscope (Jeol, Ltd., Tokyo, Japan).

Protein preparation and western blot analysis. The INS-1 cells were washed with cold PBS and harvested in radioimmunoprecipitation assay buffer (Beyotime Institute of Biotechnology) containing protease inhibitors, including phenylmethylsulfonyl fluoride (Beyotime Institute of Biotechnology) and phosphatase inhibitors (Nanjing KeyGen Biotech Co., Ltd., Nanjing, China). The cell lysates were incubated on ice for $30 \mathrm{~min}$, and then collected and centrifuged at $12,000 \mathrm{x} \mathrm{g}$ for $10 \mathrm{~min}$ at $4^{\circ} \mathrm{C}$. The supernatants were collected, mixed with $5 \mathrm{X}$ loading buffer and denatured by boiling for $10 \mathrm{~min}$. The samples were separated by sodium dodecyl sulfate-polyacrylamide gel electrophoresis $(10 \%$ gel used) and transferred onto polyvinylidene fluoride membranes at $70 \mathrm{~V}$ for $1.5 \mathrm{~h}$ in a transfer buffer containing Tris $(20 \mathrm{mM}$; bioWORLD, Dublin, OH, USA), $150 \mathrm{mM}$ glycine (Beijing Solarbio Science and Technology Co., Ltd., Beijing, China) and $20 \%$ methanol (Liaoning Xinxing Chemical Group Co., Ltd., Liaoning, China). The protein determination of the samples was made using the Bicinchoninic Acid (BCA) method; $50 \mu \mathrm{g}$ samples were loaded per lane. The membranes were incubated in non-fat dry milk for $120 \mathrm{~min}$ at room temperature, and were then washed thrice with TBST for $30 \mathrm{~min}$. The membranes were incubated with primary antibodies in TBST overnight at $4^{\circ} \mathrm{C}$. The membranes were then washed and incubated with horseradish peroxidase-conjugated anti-species secondary antibodies (1:1,000; A0208 and A0216; Beyotime Institute of Biotechnology) for $2 \mathrm{~h}$ at room temperature, and were washed thrice with TBST for $30 \mathrm{~min}$. Proteins were visualized using the BeyoECL plus kit (Beyotime Institute of Biotechnology) and quantified using Quantity One software (Bio-Rad Laboratories Inc., Hercules, CA, USA).
Statistical analysis. Data are expressed as the mean \pm standard error of the mean, and the differences between the means were analyzed by one-way analysis of variance followed by a Dunnett post hoc test. $\mathrm{P}<0.05$ was considered to indicate a statistically significant difference. Statistical analysis was performed using the Statistical Package for the Social Sciences (SPSS) 15.0 software package (SPSS, Inc., Chicago, IL, USA).

\section{Results}

GPERs are expressed in INS-1 cells. Since it has been shown GPERs are expressed in MIN6 cells (9), a mouse $\beta$-cell line, the present study aimed to detect the presence of GPERs in rat INS-1 cells. The presence of GPERs in the INS-1 cells was investigated using IF staining. As shown in Fig. 1, GPERs were present in the INS-1 cells. No GPER expression was detected in the negative controls lacking primary antibody (data not shown).

$17 \beta$-E2 regulates the PI3K/Akt pathway via the GPER in INS-1 cells. 17 $\beta$-E2 (1, 10 and $100 \mathrm{nM})$ caused the expression levels of GPER protein to increase in an apparently dose-dependent manner, with a significant increase detected at a concentration of $100 \mathrm{nM}(\mathrm{P}<0.05$; Fig. 2). In the $100 \mathrm{nM}$ group, the expression level of GPER protein was increased 2.2-fold in comparison with the control. However, the stimulatory effect of $17 \beta$-E2 was eradicated by $15 \mu \mathrm{M} \mathrm{G} 15$, a GPER-specific antagonist (Fig. 2).

The ability of $17 \beta$-E2 to regulate the PI3K/Akt pathway via the GPER in INS-1 cells was investigated via western blot analysis. The results demonstrated that $100 \mathrm{nM} 17 \beta-\mathrm{E} 2$ significantly increased the protein levels of p-Akt in INS-1 cells $(\mathrm{P}<0.05$; Fig. 3). However, the protein expression level of t-Akt remained unchanged. The effect of $17 \beta-\mathrm{E} 2$ on Akt activation in the INS-1 cells was blocked by the PI3K inhibitor LY294002 $(20 \mu \mathrm{M})$ and the GPER inhibitor G15 (15 $\mu \mathrm{M})$ (Fig. 3).

$17 \beta$-E2 protects INS-1 cells from mitophagy via the GPER. Mitophagy can be visualized by the detection of mitophagosomes or autophagosomes using TEM or the co-localization of lysosomes and mitochondria with mitophagic proteins by IF 

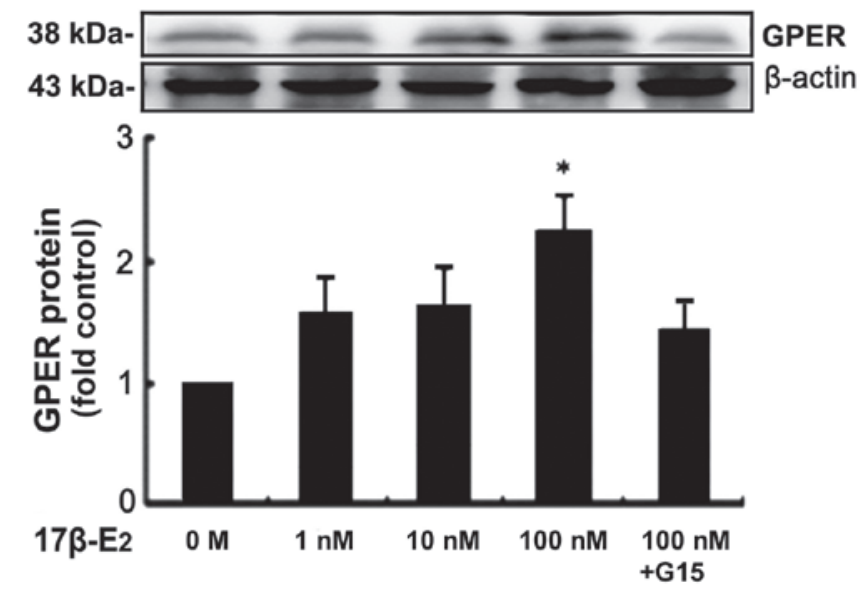

Figure 2. 17 $\beta$-E2 affects GPER expression in INS-1 cells. Serum-starved INS-1 cells were cultured with $17 \beta$-E2 at different concentrations $(0,1,10$ and $100 \mathrm{nM}$ ) with or without $15 \mu \mathrm{M}$ G15 for $24 \mathrm{~h}$. Prior to treatment with $17 \beta-E 2$, the cells were pretreated with G15 for $30 \mathrm{~min}$. Protein activation was measured by western blot analysis. Data are presented as the mean \pm standard error of the mean based on triplicate determinations from a representative experiment. ${ }^{*} \mathrm{P}<0.05$ vs. control ( $0 \mathrm{M}$ group). $17 \beta$-E2, $17 \beta$-estradiol; GPER, $\mathrm{G}$ protein-coupled estrogen receptor; INS-1, rat insulin-secreting $\beta$-cell line.

staining. Whether $17 \beta$-E2 is involved in mitophagy in INS-1 cells was investigated using these methods in the present study.

Mitophagosomes were detected in the INS-1 cells by TEM, indicating that mitophagy occurs in INS-1 cells. Compared with the control group, fewer mitophagosomes were observed in the INS-1 cells treated with 17 $\beta$-E2 (Fig. 4). Greater numbers of double-membrane vacuoles were observed in the INS-1 cells treated with $17 \beta-\mathrm{E} 2$ and G15 than that in the cells with $17 \beta$-E2 only.

In addition, the co-localization of TOM20 with LAMP2 was detected by IF staining. The results demonstrated a reduction in TOM20-positive granules and a co-localized reduction in LAMP2 expression in the INS-1 cells exposed to $17 \beta-E 2$, indicating that the numbers of mitophagosomes or autophagosomes were decreased (Fig. 5). However, these effects of $17 \beta-\mathrm{E} 2$ were eliminated by the presence of G15 (Fig. 5).

$17 \beta$-E2 is involved in mitophagy through the GPER/PI3K/Akt pathway. Whether $17 \beta$-E2 participates in mitophagy through the PI3K/Akt pathway was then investigated. The results of IF staining revealed that there were increased numbers of LAMP2-positive granules with increased TOM20 expression in the INS-1 cells treated with 17 $\beta$-E2 and LY294002 compared with the cells treated with 17 $\beta$-E2 alone (Fig. 5).

$17 \beta$-E2 regulates the expression of LC3, TOM 20 and Hsp60 in INS-1 cells. The present study suggested that $17 \beta-E 2$ may be involved in mitophagy in INS-1 cells, on the basis of the detection of mitophagosomes and autophagosomes by TEM and mitophagy-related protein co-location by IF. To further investigate this, the expression of LC3, TOM20 and Hsp60 was detected by western blot analysis. LC3-II is converted from LC3-I, and serves as a typical marker of completed autophagy (29). The exposure of INS-1 cells to $17 \beta-\mathrm{E} 2$ for $24 \mathrm{~h}$ resulted in the LC3-II protein levels being significantly reduced compared with those of the control group (Fig. 6).

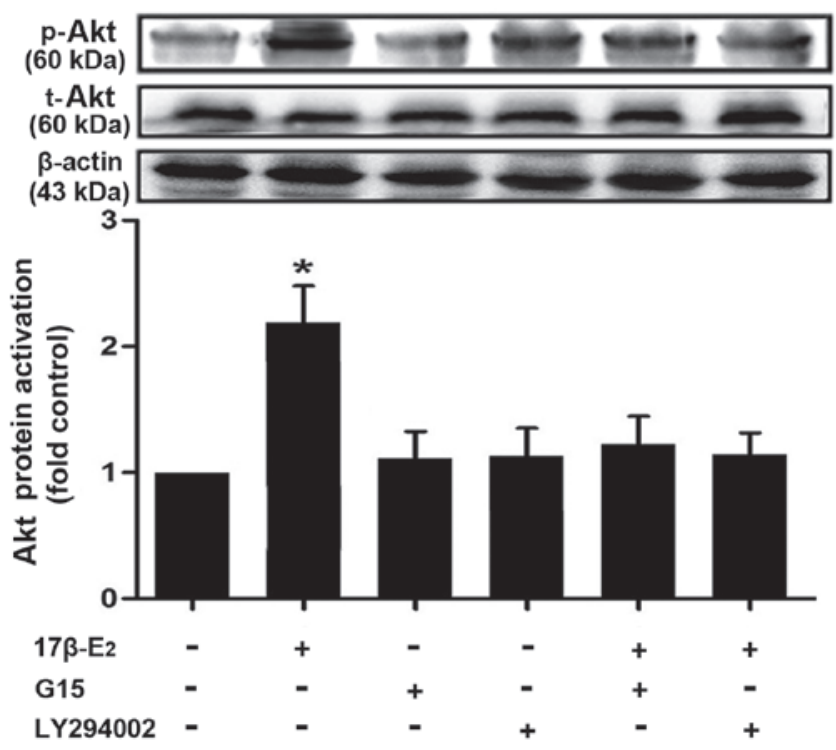

Figure 3. 17 $\beta$-E2 regulates the PI3K/Akt pathway via the GPER in INS-1 cells. Serum-starved INS-1 cells were cultured with 17 $\beta$-E2 at concentration of $100 \mathrm{nM}$ with or without $20 \mu \mathrm{M}$ LY294002 or $15 \mu \mathrm{M}$ G15 for $24 \mathrm{~h}$. Prior to treatment with $17 \beta$-E2, the cells were exposed to LY294002 or G15 for $30 \mathrm{~min}$. Protein activation was measured by western blot analysis. Data are presented as the mean \pm standard error of the mean based on triplicate determinations from a representative experiment. ${ }^{*} \mathrm{P}<0.05$ vs. control (untreated). 17 $\beta$-E2, 17 $\beta$-estradiol; PI3K, phosphoinositide 3-kinase; GPER, $\mathrm{G}$ protein-coupled estrogen receptor; INS-1, rat insulin-secreting $\beta$-cell line; p, phospho; t, total.

However, pretreatment with LY294002 or G15 attenuated the $17 \beta$-E2-induced reduction in LC3-II expression (Fig. 6). The $17 \beta$-E2 group also had significantly higher expression levels of TOM20 and Hsp60 compared with the control group (Fig. 6). However, the effect of $17 \beta-\mathrm{E} 2$ on these proteins was eradicated by pretreatment with LY294002 or G15 (Fig. 6).

\section{Discussion}

In the present study, the involvement of $17 \beta$-E2 in the process of mitophagy in INS-1 cells was investigated. The results indicated that $17 \beta$-E2 protects INS-1 cells from mitophagy, with this regulatory effect likely occurring through the GPER/PI3K/Akt pathway.

The PI3K/Akt signaling pathway is involved in almost every aspect of the physiological and pathological functions of cells, including growth, tumorigenesis, apoptosis and autophagy (30-32). The study conducted by Ropero et al (9) demonstrated that the INS-1 rat $\beta$-cell line expresses GPERs. The present study confirmed the expression of GPERs in INS-1 cells. It has been reported that E2 stimulates insulin secretion and induces glucagon secretion via the GPER in pancreatic islets (7). Therefore, the present study aimed to detect whether $17 \beta$-E2 regulates the PI3K/Akt signaling pathway via the GPER in INS-1 cells. Whether Akt phosphorylation levels are modulated by $17 \beta-E 2$ via a GPER-dependent pathway was tested in the present study. The phosphorylation level of Akt was significantly increased following stimulation with $17 \beta$-E2 for $24 \mathrm{~h}$, and the effect was blocked by pretreatment with the GPER and PI3K antagonists G15 and LY294002, respectively, for $30 \mathrm{~min}$, indicating that the activation of the 


\section{Control}

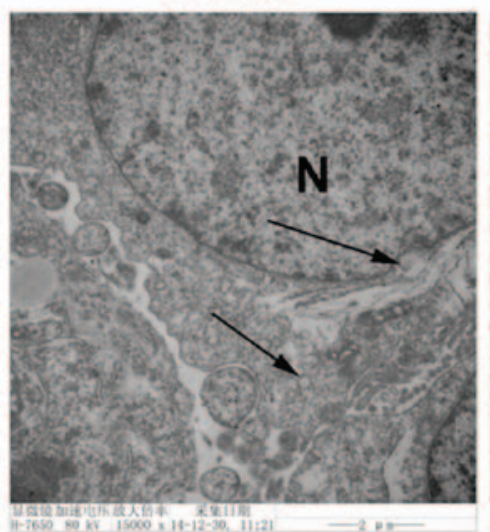

$17 \beta-E 2$

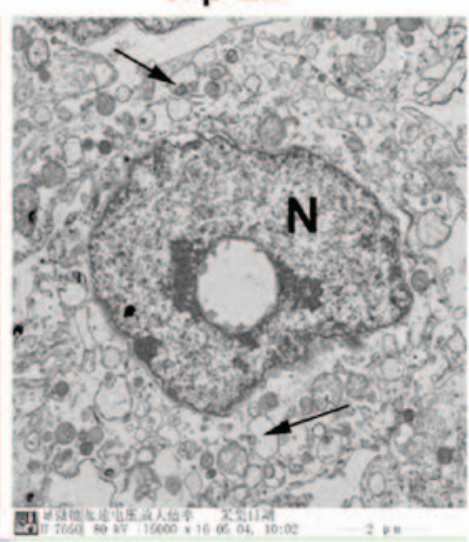

$17 \beta-E 2+G 15$

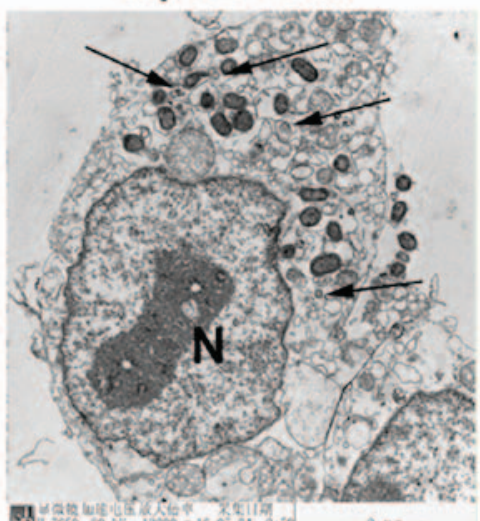

Figure 4. 17 $\beta$-E2 protects INS-1 cells from mitophagy via the GPER. Transmission electron microscopy images indicating double membrane vacuoles in INS-1 cells treated with $100 \mathrm{nM} 17 \beta-\mathrm{E} 2$ with or without the presence of $15 \mu \mathrm{M}$ G15 for $24 \mathrm{~h}$ (original magnification, $\mathrm{x} 12,000$ ). G15 was applied as a pretreatment for $30 \mathrm{~min}$. Arrows indicate vacuoles. Results are representative of three different experiments. 17 $\beta$-E2, 17 $\beta$-estradiol; INS-1, rat insulin-secreting $\beta$-cell line; GPER, G protein-coupled estrogen receptor; N, nucleus.

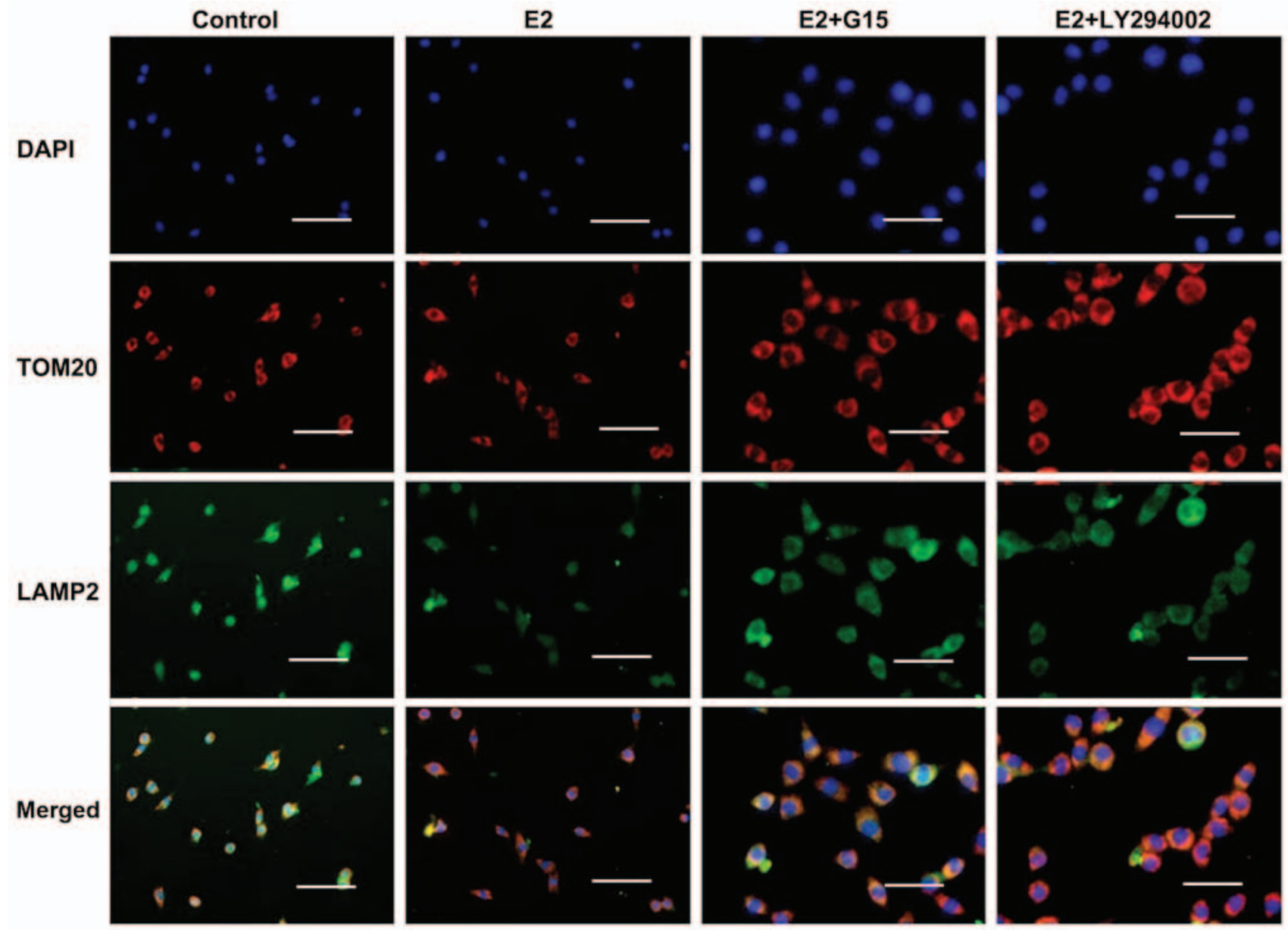

Figure 5. 17 $\beta$-E2 protectes INS-1 cells from mitophagy via the GPER. Immunofluorescence staining of TOM20 (red) and LAMP2 (green), nuclear staining (DAPI, blue) and merged images. Serum-free INS-1 cells were cultured with $17 \beta$-E2 at concentration of $100 \mathrm{nM}$ with or without G15 and LY294002 for $24 \mathrm{~h}$. Prior to treatment with 17 $\beta$-E2, the cells were exposed to G15 or LY294002 for 30 min. Results are representative of three different experiments. Scale bar, $10 \mu \mathrm{m}$. 17 $\beta$-E2, 17 $\beta$-estradiol; INS-1, rat insulin-secreting $\beta$-cell line; GPER, G protein-coupled estrogen receptor; TOM20, translocase of the mitochondrial outer membrane complex 20; LAMP2, lysosomal-associated membrane protein 2.

PI3K/Akt signaling pathway in INS-1 cells is regulated by $17 \beta-E 2$ through the GPER. Additionally, $17 \beta-E 2$ has been demonstrated to increase $\mathrm{p}$-Akt levels via the GPER in cardio- myocytes, which may rescue the heart from pathological hypertrophy (33). The rapid phosphorylation of Akt by E2 has been shown to upregulate miR144 in SkBr3 breast cancer 

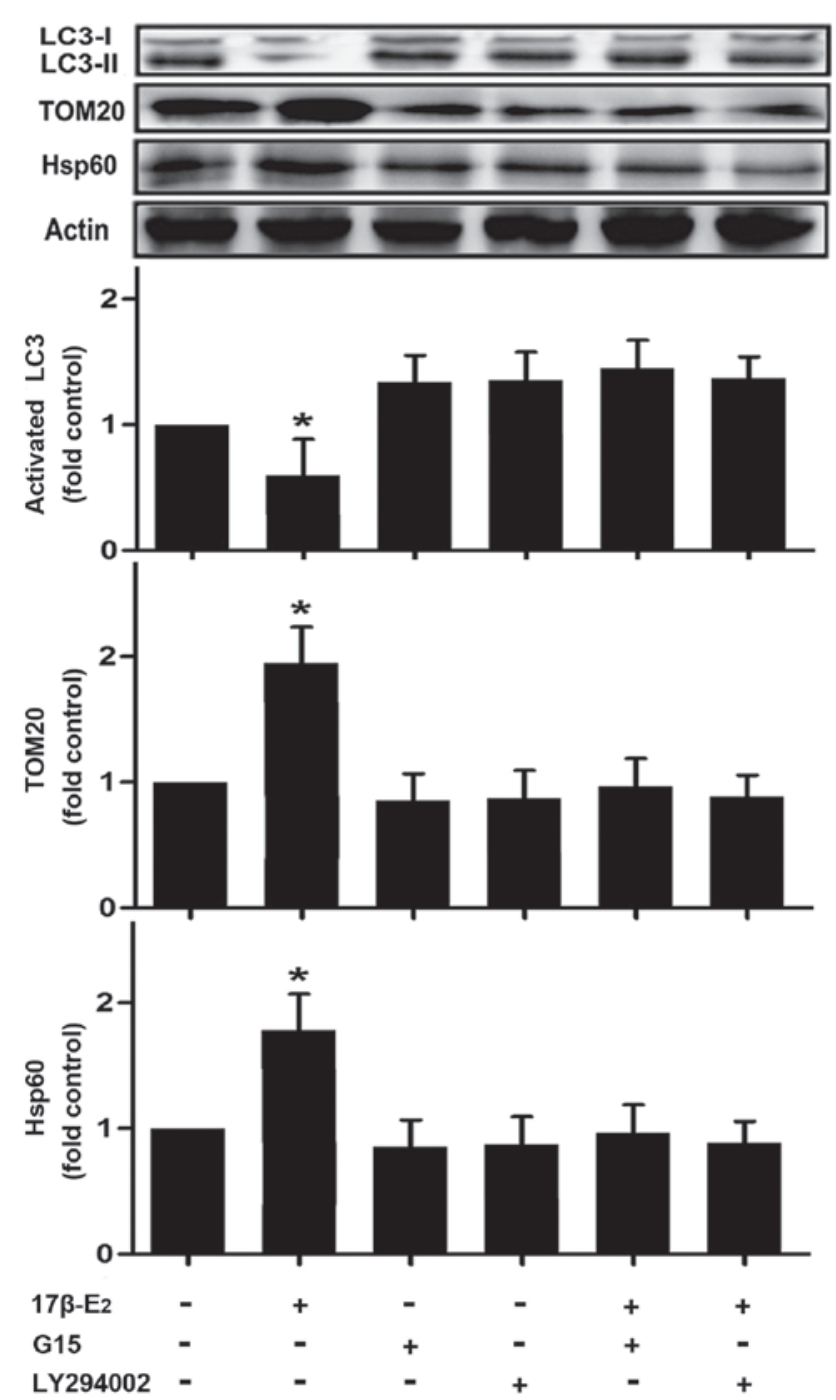

Figure 6. 17 $\beta$-E2 regulates the expression of LC3, TOM20 and Hsp60 in INS-1 cells. Serum-free INS-1 cells were treated with $100 \mathrm{nM} 17 \beta$-E2 with or without LY294002 $(20 \mu \mathrm{M})$ or G15 $(15 \mu \mathrm{M})$ for $24 \mathrm{~h}$. Prior to exposure to $17 \beta-\mathrm{E} 2$, the cells were pretreated with LY294002 or G15 for $30 \mathrm{~min}$. The protein expression was measured by western blot analysis. Data are presented as the mean \pm standard error of the mean based on triplicate determinations from a representative experiment ${ }^{*} \mathrm{P}<0.05$ vs. control (untreated). 17 $\beta$-E2, 17 $\beta$-estradiol; LC3, microtubule-associated protein-1 light chain 3; GPER, G protein-coupled estrogen receptor; TOM20, translocase of the mitochondrial outer membrane complex 20; Hsp60, mitochondrial heat-shock protein 60; INS-1, rat insulin-secreting $\beta$-cell line.

and HepG2 hepatocarcinoma cells, and this process has been indicated to occur in cancer-associated fibroblasts and cancer progression (34). Similar GPER-mediated modulatory effects of E2 on Akt phosphorylation have been demonstrated in endometrial cancer cells (35). However, E2 did not activate the PI3K/Akt pathway via the GPER in MCF-7 and MCF-10A cells (36). Therefore, the mechanism by which $17 \beta-\mathrm{E} 2$ activates the PI3K/Akt pathway remains unclear. To fully ascertain how $17 \beta$-E2 acts through the GPER, the use of a specific agonist of this receptor (such as G1) is planned in future research.

The association between $17 \beta$-E2 and mitophagy has become a topic of particular research interest. Mitochondria in pancreatic $\beta$ cells are continuously recruited in fusion and fission processes (37). In an animal model of spinal cord injury, treatment with $17 \beta-E 2$ significantly attenuated cell death (38). Furthermore, in a study conducted by Sastre-Serra et al (27), 17 $\beta$-E2 increased mitochondrial fusion, decreased fission processes, and modified the normal development and functions of mitochondria in MCF-7 breast cancer cells through estrogen receptors. In the present study, 17 $\beta$-E2 was demonstrated to protect INS-1 cells from mitophagy via the GPER. The presence of mitochondria in autophagosomes (mitophagosomes) was identified using TEM, which indicates that mitophagy occurs in INS-1 cells. TEM analysis demonstrated that there were few mitophagosomes and scarcely any autophagomes in the INS-1 cells treated with $17 \beta-E 2$. However, the number of mitophagosomes and autophagomes was increased in the INS-1 cells cultured with $17 \beta-E 2$ following pretreatment with G15. Therefore, it is suggested that the protective effect of $17 \beta-\mathrm{E} 2$ against mitophagy may occur through the activation of the GPER. This observation may be associated with inhibitory effect of $17 \beta$-E2 on the mitochondrial fission process, and may also indicate that the GPER serves an important role in this protective process.

It has been reported that PI3K/Akt signal transduction prevents cells from undergoing apoptosis $(30,39)$. The PI3K/Akt pathway, the p38 mitogen-activated protein kinase signaling pathway, and reactive oxygen species participate in wogonoside-induced autophagy and apoptosis (40). Inactivation of the PI3K/Akt pathway prevents the translocation of damageregulated autophagy modulator to the mitochondria and induces apoptosis in hepatocellular carcinoma cells by the mediation of mitophagy (41). Furthermore, inhibition of the PI3K/Akt/mTOR signaling pathway is accompanied by autophagy and mitophagy in human glioblastoma cells, glioblastoma stem cells and human prostate cancer $(42,43)$. In the present study, the results indicated that $17 \beta-E 2$ regulated mitophagy in INS-1 cells through the GPER/PI3K/Akt pathway. In addition, IF analysis of the INS-1 cells revealed that $17 \beta$-E2 reduced the number of LAMP2-labeled lysosomes that were co-localized with TOM20-labeled mitochondria in comparison with the cells treated with 17 $\beta$-E2 following G15 or LY294002 pretreatment, which exhibited an increased presence of mitophagosomes, indicating that 17 $\beta$-E2 alone reduced the formation of mitophagosomes. These results are consistent with the TEM results of the present study. Therefore, it is suggested that the PI3K/Akt pathway is also involved in the mechanistic pathway by which $17 \beta-\mathrm{E} 2$ exerts a protective effect on INS-1 cells via the GPER. Furthermore, the results of western blot analysis also supported this suggestion. As shown in Fig. 6, the expression of LC3-II was decreased and the expression of TOM20 and Hsp60 was increased in INS-1 cells exposed to 17 $\beta$-E2, and this was partially consistent with the observations concerning the $17 \beta$-E2-induced suppression of mitophagy in INS-1 cells. mTOR is a downstream factor of the PI3K/Akt signaling pathway, which has an important role in the modulation of mitophagy (44-46). The inhibition of mTOR increases mitophagic activity through a ubiquitin-like-conjugating enzyme ATG3-dependent mechanism in natural killer cells (47). Therefore, it is hypothesized that $17 \beta$-E2 activates the PI3K/Akt signaling pathway by means of the GPER, which may subsequently inhibit mitophagy via the regulation of mTOR.

In conclusion, the results of the present study demonstrate that $17 \beta$-E2 protects INS-1 rat insulinoma cells from mitophagy via the GPER and acts through the PI3K/Akt signaling pathway. These results provide novel insights for understanding the pathophysiological functions of the GPER in pancreatic $\beta$ cells. 


\section{Acknowledgements}

The authors would like to thank the China Medical University Affiliated Hospital Laboratory Center for kindly providing the equipment. The present study was supported by the National Natural Science Foundation of China (grant nos. 81470998, 81071460 and 81271996).

\section{Competing interests}

The authors declare that they have no competing interests.

\section{References}

1. Kahn SE,Zraika S, Utzschneider KM and Hull RL: The beta cell lesion in type 2 diabetes: There has to be a primary functional abnormality. Diabetologia 52: 1003-1012, 2009.

2. Marchetti P, Dotta F, Lauro D and Purrello F: An overview of pancreatic beta-cell defects in human type 2 diabetes: Implications for treatment. Regul Pept 146: 4-11, 2008.

3. Prentki M and Nolan CJ: Islet beta cell failure in type 2 diabetes. J Clin Invest 116: 1802-1812, 2006.

4. Geisler JG, Zawalich W, Zawalich K, Lakey JR, Stukenbrok H, Milici AJ and Soeller WC: Estrogen can prevent or reverse obesity and diabetes in mice expressing human islet amyloid polypeptide. Diabetes 51: 2158-2169, 2002.

5. Nadal A, Ropero AB, Laribi O, Maillet M, Fuentes E and Soria B: Nongenomic actions of estrogens and xenoestrogens by binding at a plasma membrane receptor unrelated to estrogen receptor alpha and estrogen receptor beta. Proc Natl Acad Sci USA 97: 11603-11608, 2000.

6. Ropero AB, Soria B and Nadal A: A nonclassical estrogen membrane receptor triggers rapid differential actions in the endocrine pancreas. Mol Endocrinol 16: 497-505, 2002.

7. Mårtensson UE, Salehi SA, Windahl S, Gomez MF, Swärd K, Daszkiewicz-Nilsson J, Wendt A, Andersson N, Hellstrand P, Grände PO, et al: Deletion of the $\mathrm{G}$ protein-coupled receptor 30 impairs glucose tolerance, reduces bone growth, increases blood pressure, and eliminates estradiol-stimulated insulin release in female mice. Endocrinology 150: 687-698, 2009.

8. Sharma G and Prossnitz ER: Mechanisms of estradiol-induced insulin secretion by the $G$ protein-coupled estrogen receptor GPR30/GPER in pancreatic beta-cells. Endocrinology 152: 3030-3039, 2011.

9. Ropero AB, Pang Y, Alonso-Magdalena P, Thomas P and Nadal A: Role of ER $\beta$ and GPR30 in the endocrine pancreas: A matter of estrogen dose. Steroids 77: 951-958, 2012.

10. Alexander SP, Davenport AP, Kelly E, Marrion N, Peters JA, Benson HE, Faccenda E, Pawson AJ, Sharman JL, Southan C, et al; CGTP Collaborators: The Concise Guide to PHARMACOLOGY 2015/16: G protein-coupled receptors. Br J Pharmacol 172: 57445869,2015

11. Revankar CM, Cimino DF, Sklar LA, Arterburn JB and Prossnitz ER: A transmembrane intracellular estrogen receptor mediates rapid cell signaling. Science 307: 1625-1630, 2005.

12. Prossnitz ER and Barton M: The G-protein-coupled estrogen receptor GPER in health and disease. Nat Rev Endocrinol 7: 715-726, 2011.

13. Suire S, Condliffe AM, Ferguson GJ, Ellson CD, Guillou H, Davidson K, Welch H, Coadwell J, Turner M, Chilvers ER, et al: Gbetagammas and the Ras binding domain of p110gamma are both important regulators of PI(3)Kgamma signalling in neutrophils. Nat Cell Biol 8: 1303-1309, 2006.

14. Dbouk HA, Vadas O, Shymanets A, Burke JE, Salamon RS, Khalil BD, Barrett MO, Waldo GL, Surve C, Hsueh C, et al: $\mathrm{G}$ protein-coupled receptor-mediated activation of $\mathrm{p} 110 \beta$ by $\mathrm{G} \beta \gamma$ is required for cellular transformation and invasiveness. Sci Signal 5: ra89, 2012.

15. Durand CA, Hartvigsen K, Fogelstrand L, Kim S, Iritani S, Vanhaesebroeck B, Witztum JL, Puri KD and Gold MR: Phosphoinositide 3-kinase p110 delta regulates natural antibody production, marginal zone and B-1 B cell function, and autoantibody responses. J Immunol 183: 5673-5684, 2009.

16. De Duve C and Wattiaux R: Functions of lysosomes. Annu Rev Physiol 28: 435-492, 1966.
17. Clark SL Jr: Cellular differentiation in the kidneys of newborn mice studies with the electron microscope. J Biophys Biochem Cytol 3: 349-362, 1957.

18. Choi AM, Ryter SW and Levine B: Autophagy in human health and disease. N Engl J Med 368: 1845-1846, 2013

19. Janku F, McConkey DJ, Hong DS and Kurzrock R: Autophagy as a target for anticancer therapy. Nat Rev Clin Oncol 8: 528-539, 2011.

20. Carayol N, Vakana E, Sassano A, Kaur S, Goussetis DJ, Glaser H, Druker BJ, Donato NJ, Altman JK, Barr S, et al: Critical roles for mTORC2- and rapamycin-insensitive mTORC1-complexes in growth and survival of BCR-ABL-expressing leukemic cells. Proc Natl Acad Sci USA 107: 12469-12474, 2010.

21. Fan QW, Cheng C, Hackett C, Feldman M, Houseman BT, Nicolaides T, Haas-Kogan D, James CD, Oakes SA, Debnath J, et al: Akt and autophagy cooperate to promote survival of drugresistant glioma. Sci Signal 3: ra81, 2010.

22. Lemasters JJ: Selective mitochondrial autophagy, or mitophagy, as a targeted defense against oxidative stress, mitochondrial dysfunction, and aging. Rejuvenation Res 8: 3-5, 2005.

23. Mitchell T, Chacko B, Ballinger SW, Bailey SM, Zhang J and Darley-Usmar V: Convergent mechanisms for dysregulation of mitochondrial quality control in metabolic disease: Implications for mitochondrial therapeutics. Biochem Soc Trans 41: 127-133, 2013.

24. Andersson SG,Zomorodipour A, Andersson JO, Sicheritz-Pontén T, Alsmark UC, Podowski RM, Näslund AK, Eriksson AS, Winkler HH and Kurland CG: The genome sequence of Rickettsia prowazekii and the origin of mitochondria. Nature 396: 133-140, 1998.

25. Kim I and Lemasters JJ: Mitochondrial degradation by autophagy (mitophagy) in GFP-LC3 transgenic hepatocytes during nutrient deprivation. Am J Physiol Cell Physiol 300: C308-C317, 2011.

26. Twig G and Shirihai OS: The interplay between mitochondrial dynamics and mitophagy. Antioxid Redox Signal 14: 1939-1951, 2011.

27. Sastre-Serra J, Nadal-Serrano M, Pons DG, Roca P and Oliver J: Mitochondrial dynamics is affected by $17 \beta$-estradiol in the MCF-7 breast cancer cell line. Effects on fusion and fission related genes. Int J Biochem Cell Biol 44: 1901-1905, 2012.

28. Zhang J: Teaching the basics of autophagy and mitophagy to redox biologists - mechanisms and experimental approaches. Redox Biol 4: 242-259, 2015.

29. Kabeya Y, Mizushima N, Ueno T, Yamamoto A, Kirisako T, Noda T, Kominami E, Ohsumi Y and Yoshimori T: LC3, a mammalian homologue of yeast Apg8p, is localized in autophagosome membranes after processing. EMBO J 19: 5720-5728, 2000.

30. Chang F, Lee JT, Navolanic PM, Steelman LS, Shelton JG, Blalock WL, Franklin RA and McCubrey JA: Involvement of PI3K/Akt pathway in cell cycle progression, apoptosis, and neoplastic transformation: A target for cancer chemotherapy. Leukemia 17: 590-603, 2003.

31. Manning BD and Cantley LC: AKT/PKB signaling: Navigating downstream. Cell 129: 1261-1274, 2007.

32. Brazil DP, Yang ZZ and Hemmings BA: Advances in protein kinase $B$ signalling: AKTion on multiple fronts. Trends Biochem Sci 29: 233-242, 2004.

33. Lee TM, Lin SZ and Chang NC: Both GPER and membrane oestrogen receptor- $\alpha$ activation protect ventricular remodelling in $17 \beta$ oestradiol-treated ovariectomized infarcted rats. J Cell Mol Med 18: 2454-2465, 2014.

34. Vivacqua A, De Marco P, Santolla MF, Cirillo F, Pellegrino M, Panno ML, Abonante S and Maggiolini M: Estrogenic gper signaling regulates mirl44 expression in cancer cells and cancerassociated fibroblasts (cafs). Oncotarget 6: 16573-16587, 2015.

35. Tsai CL, Wu HM, Lin CY, Lin YJ, Chao A, Wang TH, Hsueh S, Lai $\mathrm{CH}$ and Wang HS: Estradiol and tamoxifen induce cell migration through GPR30 and activation of focal adhesion kinase (FAK) in endometrial cancers with low or without nuclear estrogen receptor $\alpha(E R \alpha)$. PLoS One 8: e72999, 2013.

36. Wróbel AM and Gregoraszczuk EL: Action of methyl-, propyland butylparaben on GPR30 gene and protein expression, cAMP levels and activation of ERK1/2 and PI3K/Akt signaling pathways in MCF-7 breast cancer cells and MCF-10A non-transformed breast epithelial cells. Toxicol Lett 238: 110-116, 2015.

37. Stiles L and Shirihai OS: Mitochondrial dynamics and morphology in beta-cells. Best Pract Res Clin Endocrinol Metab 26: 725-738, 2012.

38. Sribnick EA, Matzelle DD, Ray SK and Banik NL: Estrogen treatment of spinal cord injury attenuates calpain activation and apoptosis. J Neurosci Res 84: 1064-1075, 2006. 
39. Jiang $\mathrm{H}$, Zhang J, Zhu $\mathrm{H}$, Li H and Zhang X: Nerve growth factor prevents the apoptosis-associated increase in acetylcholinesterase activity after hydrogen peroxide treatment by activating Akt. Acta Biochim Biophys Sin (Shanghai) 39: 46-56, 2007.

40. Zhang L, Wang H, Cong Z, Xu J, Zhu J, Ji X and Ding K: Wogonoside induces autophagy-related apoptosis in human glioblastoma cells. Oncol Rep 32: 1179-1187, 2014.

41. Liu K, Shi Y, Guo XH, Ouyang YB, Wang SS, Liu DJ, Wang AN, Li N and Chen DX: Phosphorylated AKT inhibits the apoptosis induced by DRAM-mediated mitophagy in hepatocellular carcinoma by preventing the translocation of DRAM to mitochondria. Cell Death Dis 5: e1078, 2014.

42. Ma J, Meng F, Li S, Liu L, Zhao L, Liu Y, Hu Y, Li Z, Yao Y, $\mathrm{Xi} \mathrm{Z}$, et al: Autophagy induction by endothelial-monocyte activating polypeptide II contributes to the inhibition of malignant biological behaviors by the combination of EMAP II with rapamycin in human glioblastoma. Front Mol Neurosci 8: 74, 2015.
43. Liu YQ, Ji Y, Li XZ, Tian KL, Young CY, Lou HX and Yuan HQ: Retigeric acid B-induced mitophagy by oxidative stress attenuates cell death against prostate cancer cells in vitro. Acta Pharmacol Sin 34: 1183-1191, 2013

44. Chen G, Ke Z, Xu M, Liao M, Wang X, Qi Y, Zhang T, Frank JA, Bower KA, Shi X, et al: Autophagy is a protective response to ethanol neurotoxicity. Autophagy 8: 1577-1589, 2012.

45. Zhuang W, Qin Z and Liang Z: The role of autophagy in sensitizing malignant glioma cells to radiation therapy. Acta Biochim Biophys Sin (Shanghai) 41: 341-351, 2009.

46. Edinger AL and Thompson CB: An activated mTOR mutant supports growth factor-independent, nutrient-dependent cell survival. Oncogene 23: 5654-5663, 2004.

47. O'Sullivan TE, Johnson LR, Kang HH and Sun JC: BNIP3- and BNIP3L-mediated mitophagy promotes the generation of natural killer cell memory. Immunity 43: 331-342, 2015. 